\title{
A NEW APPARATUS AND METHOD FOR PUNCTUR- ING THE SUPERIOR LONGITUDINAL SINUS IN INFANTS *
}

\author{
A. BRET RATNER, M.D. \\ NEW YORK
}

The use of the superior longitudinal sinus to obtain blood for examination and as a path for intravenous injections is attended with many advantages. These advantages are readily appreciated and are emphasized in a number of recent papers. The first to use this vessel was Marfan, ${ }^{1}$ in 1898, for the introduction of salt solution in a case of cholera infantum. Nothing further appeared in the literature regarding its use until 1915, when Tobler ${ }^{2}$ studied the anatomic relations of the sinus for this purpose. While sinus therapy is now generally regarded a safe procedure, the fact, however, that the sinus is hidden from view, and that there is danger of infiltration into the brain when injecting fluid, justifies a consideration of technic.

Goldbloom, ${ }^{3}$ in 1918, devised an apparatus which was an improve ment upon several which preceded it. In March, 1920, he ${ }^{4}$ describer a new apparatus in which the block was beveled at an angle of $5 \mathrm{C}$ degrees. The great disadvantage of Goldbloom's apparatus is that the block is so large (and the beveled block gives even a larger surface) that it entirely obliterates the point of the needle from view. It is obvious, therefore, that to insert the needle into the exact spot decided on is somewhat a matter of chance. The fact that in the improved apparatus the needle enters at an angle of 50 degrees does not eliminate the possibility of injury to the sinus wall, as the angle is not sufficiently acute to make the needle run parallel with the sinus after it has been entered. If the needle has been set too long and put in obliquely, it may transfix or penetrate the wall of the sinus. Other disadvantages are that the apparatus is very expensive and a special needle is required should it become too dull for use.

* Received for publication, Sept. 2, 1920.

* From the Pediatric Service of the New York Nursery and Child's Hospital and the Department of Pediatrics, Cornell University Medical College.

1. Marfan (from Blechmann, G.) : Technique des prélévéments de sang et des injections intraveineuses chez les nourrissons, Le Nourrisson 2:150, 1914.

2. Tobler, L.: Zur technic der diagnostischen blutentnahme und der intravenösen injection beim saügling, Monatschr. f. Kinderh. 13:384, 1915.

3. Goldbloom, A.: A New Apparatus for Puncture of the Superior Longitudinal Sinus, Am. J. Dis. Child. 16:388 (Nov.) 1918.

4. Goldbloom, A.: An Improved Needle for Sinus Therapy, Am. J. Dis. Child. 19:229 (March) 1920 . 
Owing to disadvantages of the various methods in use, I have devised an apparatus which is simple, inexpensive and presents, I believe, many advantages. It has been used on a large number of infants in the New York Nursery and Child's Hospital and has proved satisfactory.

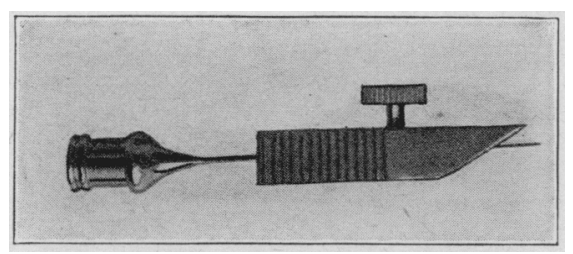

Fig. 1.--Author's Apparatus.

It consists of a small metal block, $1 / 4$ of an inch square by $1 \frac{1}{4}$ inches long, with an acutely beveled base. An opening of 18 gage bore runs through the middle of the block which permits the insertion of the needle. A thumb screw is provided which holds the needle securely in place after it has been adjusted to the desired length. The needle is $13 / 8$ inches long with a Luer-slip hub and a short beveled point.

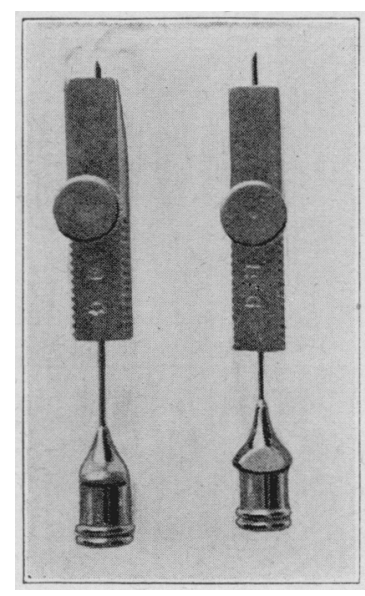

Figure 2

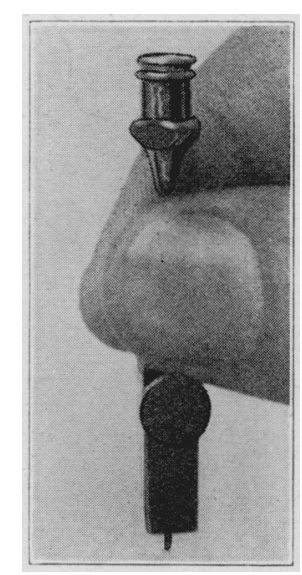

Figure 3

Fig. 2.-Position to adjust length of needle.

Fig. 3.-First step for injecting fluid.

The first step in using the apparatus is to determine the length of the needle necessary to just enter the sinus. There is no exact way of doing this as the depth of the sinus varies somewhat in different infants. A method which $I$ have found helpful is to pinch up a portion of the scalp and half the thickness of the fold gives the approximate depth into the sinus. With the needle as in Figure 2, it is adjusted to the length decided on and the set screw is tightened, keeping 
the bevel of the needle in the same direction as the bevel of the block. Tobler's measurements show that the distance from the skin to the sinus is from 2 to $5 \mathrm{~mm}$. and the depth-at the posterior angle-varies between 4 and $7 \mathrm{~mm}$., depending on the age and size of the infant. This would give a range of from 3 to $6 \mathrm{~mm}$. to just enter the sinus in the various cases. Keeping these figures in mind serves as a control.

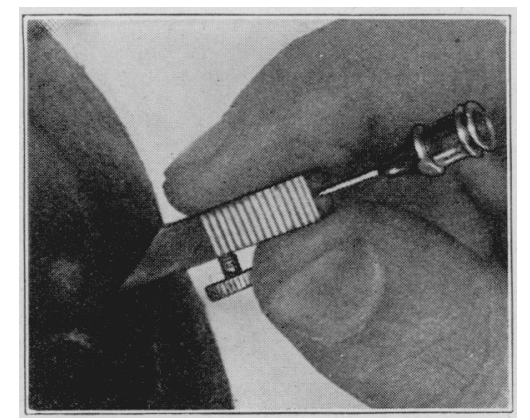

Fig. 4.-Second step for injecting fluid.

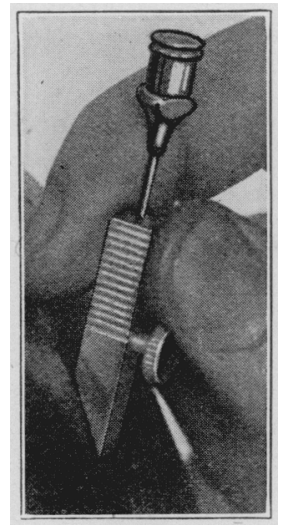

Figure 5

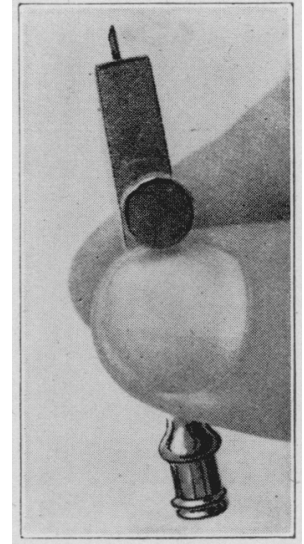

Figure 6

Fig. 5.-Third step for injecting fluid.

Fig. 6.-First step for collecting blood.

The point of entrance is chosen near the posterior angle of the fontanel along an imaginary line drawn between the middle of the bridge of the nose and the posterior angle of the fontanel. For the administration of fluid the apparatus, held as in Figure 3, is forced in -at the point decided on-up to the end of the block (Fig. 4). If one has successfully entered the sinus, there will be an immediate and steady flow of blood, and now using the end of the block as a fulcrum, the apparatus is quickly turned so as to bring the beveled 
surface of the block in close apposition to the scalp (Fig. 5). A syringe or gravity apparatus is immediately attached to the hub, and the fluid is administered in the usual manner. When the operation is completed, the needle is pulled out, a compress is held firmly over the bleeding point, and the child is raised to a sitting position. After the bleeding has stopped, collodion is applied. For the collection of blood the apparatus is used as shown in Figures 6,7 and 8.

If one has not entered the sintis successfully, the needle may have been set too short or too long. It may have become blocked, or it may have been inserted outside the sinus. Under such conditions it is time saving immediately to withdraw the needle, determine where the fault lies and correct it. Whenever the needle has been used, it shou!d immediately be cleansed with rumning cold water;

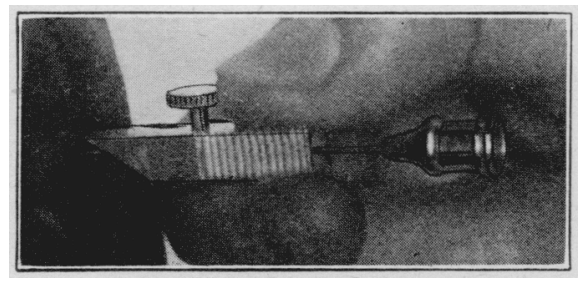

Figure 7

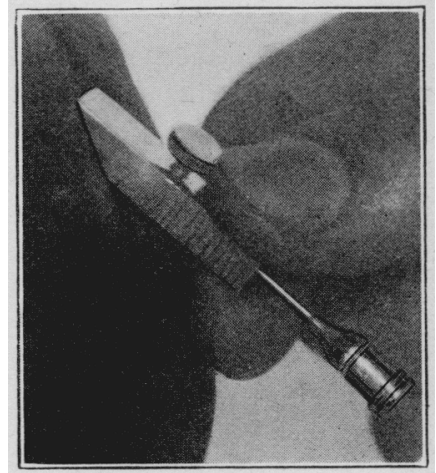

Figure 8

Fig. 7.-Second step for collecting blood.

Fig. 8.-Third step for collecting blood.

the wire run through with a cleaning powder or sapolio until the lumen is clean, rinsed in cold water, then alcohol, and finally immersed in ether. This will keep the apparatus in perfect condition and obviate another cause of faulty venipuncture.

The advantages of this apparatus are that it is of simple construction; the needle is always in view when inserting it; it can be held comfortably and firmly in place. The end of the block prevents the needle from entering too far and serves as a fulcrum upon which the block turns, automatically causing the needle to assume a plane in the direction of the sinus. The beveled surface lying flat against the scalp prevents lateral movement and keeps the needle in a constant position. Any ordinary needle with a short bevel up to an 18 gage can be used.

I am indebted to the Randall-Faichney Company, Boston, for the manufacture of the apparatus. 